\title{
Descriptive analysis of the type and design of contact lenses fitted according to keratoconus severity and morphology
}

\author{
Análise descritiva dos tipos e parâmetros das lentes de contato adaptadas \\ de acordo com o grau evolutivo e a morfologia do ceratocone
}

Letícia Helena lunardi ${ }^{1}$, Danielle Arroyo ${ }^{1}$, Marcelo Vicente de Andrade Sobrinho ${ }^{1}$, César Lipener ${ }^{1}$, Juliana Maria da Silva Rosa ${ }^{1}$

\begin{abstract}
Purpose: Keratoconus is characterized by bilateral asymmetrical corneal ectasia that leads to inferior stromal thinning and corneal protrusion. There is currently a lack of consensus regarding the most efficacious method for fitting contact lenses in patients with keratoconus, given the various topographical patterns and evolution grades observed in affected populations. The purpose of the present study was to evaluate the association between keratoconus evolution grade and topography pattern and the type and design of fitted contact lens.

Methods: We performed a retrospective analysis of contact lenses fitted in a total of 185 patients with keratoconus (325 eyes). Keratoconus was classified as either grade I, II, III, or IV based on keratometry and cone morphology (nipple, oval, globus, or indeterminate) results.

Results: A total of 325 eyes were evaluated in the present study. Of the 62 eyes classified as grade I, $66.1 \%$ were fitted with monocurve contact lenses. Of the 162 eyes classified as grade I and II, 51\%, 30\%, and 19\% were fitted with adapted monocurve rigid gas-permeable contact lenses (RGPCL), bicurve lenses, and others lens types, respectively. Bicurve lenses were fitted in $52.1 \%$ and $62.2 \%$ of eyes classified as grade III and IV, respectively. Of the eyes classified as grade III and IV, monocurve and bicurve RGPCL were fitted in $26 \%$ and $55 \%$, respectively. In eyes with oval keratoconus, 45\%,35\%, and 20\% were fitted with monocurve lenses, bicurve lenses, and other lens types, respectively. In eyes with round cones (nipple morphology), 55\%, 30\%, and 15\% were fitted with bicurve lenses, monocurve lenses, and other lens types, respectively.

Conclusion: Monocurve RGPCL were most frequently fitted in patients with mild to moderate keratoconus and oval cones morphology, while bicurve lenses were more frequently fitted in patients with severe and advanced keratoconus. This was probably because bicurve lenses are more appropriate for round cones due to increased corneal asphericity.
\end{abstract}

Keywords: Corneal diseases; Keratoconus; Keratoconus/classification; Contact lenses; Equipment design

\section{RESUMO}

Objetivo: O ceratocone é uma ectasia corneana bilateral e assimétrica que leva a afinamento corneano inferior e protrusão da córnea, não existe consenso sobre qual é o melhor caminho para adaptar lentes de contato em pacientes com ceratocone, considerando seus diferentes padrões topográficos e graus de evolução. O objetivo desse estudo é associar o grau de evolução e padrão topográfico com o tipo/desenho da lente adaptada.

Métodos: Análise retrospectiva das lentes de contato adaptadas em 185 pacientes com ceratocone (325 olhos) no Departamento de Lentes de Contato. O ceratocone foi classificado de acordo com a ceratometria em graus I, II, III e IV e de acordo com a morfologia em cone redondo, oval, globoso e indeterminado.

Resultados: Foram avaliados 325 olhos. Em 66, 1 \% dos ol hos com grau Ifoi adaptada lente monocurva. Dos 162 olhos classificados como graus le ll foram adaptadas lentes monocurva em 51\%, bicurva em $30 \%$ e outros em $19 \%$. Em relação aos olhos grau III, em 52,1\% foram adaptadas lentes bicurvas e o mesmo aconteceu em 62,2\% dos ol hos com grau IV. Apenas $26 \%$ dos ol hos grau III ou IV receberam lentes monocurva, com necessidade de bicurvas em 55\%. 45\% dos cones ovais foram adaptados com lentes monocurva, 35\% com bicurvas e 20\% com outros tipos, enquanto 55\% dos cones redondos foram adaptados com lentes bicurvas, apenas 30\% com monocurvas e 15\% com outros desenhos.

Conclusão: Lentes de contato rígida gás-permeável (LCRGP) monocurvas são mais frequentemente utilizadas em ceratocones leves e moderados e em ovais, enquanto bicurvas são mais usadas para casos graves e avançados e em cones redondos.

Descritores: Doenças da córnea; Ceratocone; Ceratocone/classificação; Lentes de contato; Desenho de equipamento

\section{INTRODUCTION}

Keratoconus is characterized by bilateral asymmetrical non-inflammatory corneal ectasia that leads to central or inferotemporal stromal thinning, corneal protrusion (which may be surrounded by iron deposits in the epithelial basement membrane), and rupture of
Bowman's layer. Irregular corneal astigmatism may result in significant visual loss in approximately 1 per 2000 individuals in the general population, with a diagnosis usually made in the second decade of life ${ }^{(1,2)}$. Keratoconus morphology may be categorized as: nipple cones, $5-\mathrm{mm}$ diameter, with the apex localized centrally or paracentrally
Funding: No specific financial support was available for this study.

Disclosure of potential conflicts of interest: None of the authors have any potential conflicts of interest to disclose

Corresponding author: Juliana Maria da Silva Rosa. Av. João Carlos Machado, 455/202 - Rio de Janeiro, RJ - 22620-081 - Brazil - E-mail: jumsrosa@gmail.com

Approved by the following research ethics committee: UNIFESP, Plataforma Brasil (CAAE 14862113.7.0000.5505). 
often displaced inferonasally; oval cones, 5 to 6-mm diameter, with inferotemporally ellipsoid profile; and globus cones, more than $6-\mathrm{mm}$ diameter, occupying more than $75 \%$ of the cornea ${ }^{(3)}$.

The use of rigid glass contact lenses was first described in 1888 by Adolf Fick. Contact lens fitting remains the most appropriate option for correcting refractive errors induced by keratoconus, as this approach regularizes the corneal surface, thereby ensuring maximum visual acuity with decreased residual aberration. Contact lenses provide superior amount and quality of vision as compared to spectacles ${ }^{(4,5)}$. In their multicenter analysis of patients with keratoconus, Lass et al. reported that $74 \%$ do not require surgery and can be managed with either contact lenses (84\%) or spectacles (13\%), or without correction $(3 \%)^{(6)}$. Bilgin et al. reported a success rate of $98.9 \%$ in 1004 patients fitted with contact lenses over a 30-year period ${ }^{(7)}$

Rigid gas-permeable contact lenses (RGPCL) remain the most commonly used type of lens and are available in several designs, including bicurve and multicurve. The development of new lenses and designs has enabled improvements in visual acuity and either prevented or postponed the need for surgical intervention in an increased number of patients ${ }^{(6)}$. However, there is currently a lack of consensus regarding the most efficacious method for fitting contact lenses in patients with keratoconus, given the various topographical patterns and evolution grades observed in affected populations.

The purpose of the present study was to evaluate the association between keratoconus evolution grade and topography pattern and the type and design of fitted contact lens.

\section{METHODS}

A retrospective analysis of 185 patients with keratoconus (325 eyes) fitted with contact lenses between 2007 and 2010 was conducted at the Contact Lens Sector, Paulista School of Medicine, Federal University of São Paulo (EPM/UNIFESP). Diagnoses were made by the Cornea Department. Age, gender, keratometry, base curve, and lens diameter were recorded. Keratoconus was classified according to keratometry (K1) as either incipient or grade I $(K<45.00 \mathrm{D}$ in both meridians), moderate or grade II (K between 45.00 and $52.00 \mathrm{D}$ in both meridians), advanced or grade III (K between 52.00 and $62.00 \mathrm{D}$ in both meridians), and severe or grade IV (K>62.00 D in both meridians) and according to cone morphology (nipple, oval, globus, or indeterminate). All patients were initially fitted with monocurve (spherical or aspherical) RGPCL with only one central base curve. In cases with unsuccessful initial lens fitting (due to contact lenses with excessive apical bearing, excessive peripheral seal-off, excessive pooling, or patient intolerance), the type and/or lens design was modified to one of the following: bicurve RGPCL (designed by Joseph Soper), with a characteristic variable central curve and a constant (45.00 D) intermediate curve; multicurve lens, a variation of the Soper design with 2 or more intermediate curves or aspherical flattening from the central till the peripheral curve; or multispherical lens, with a characteristic single spherical central area, approximately $5 \mathrm{~mm}$ in size, with multiple flatter spherical peripheral curves. Adaptation with soft contact lenses for keratoconus correction was attempted in patients that were intolerant to rigid contact lenses. Analyses for descriptive data were performed. Continuous variables are presented as means \pm standard deviation. Categorical variables are presented as frequencies. Between-group differences were analyzed using the chi-square test. The SigmaPlot 11.0 software package was used for all statistical analyses with the significance level set to $5 \%$.

\section{RESULTS}

A total of 325 eyes were evaluated in the present study. The average patient age was $24.7 \pm 8.5$ years. Topography-derived mean K1 and K2 were $47.96 \pm 6.75$ and $52.43 \pm 8.5$, respectively. The mean base curve of soft contact lenses and RGPCL was $40.66 \pm 2.84$ and
$48.8 \pm 4.5$ diopters, respectively. The mean visual acuity was $0.5 \pm 0.3$ (logMAR) with refraction and $0.2 \pm 0.1$ with contact lenses $(P<0.05)$. The mean diameter of rigid contact lenses was $9.1 \pm 4.1 \mathrm{~mm}$ (Table 1). Bicurve contact lenses were fitted in 138 (42.4\%), monocurve lenses in 126 (38.8\%), and multicurve lenses in 45 (13.8\%) eyes. Soft contact lenses were fitted in 7 (2.1\%); keratoconus special soft contact lenses (Perfect Keratoconus, World Vision, São Paulo, Brazil) in 2 (0.6\%); multispherical (Century, Optolentes, Porto Alegre, Brazil) in 6 (1.8\%); and reverse curve design contact lenses (Ultraflat, Ultralentes, Porto Alegre, Brazil) in 1 eye/s (0.3\%, Table 2$)$.

Sixty-two eyes were classified as grade I (19.07\%), 97 as grade II (29.8\%), 121 as grade III (37.2\%), and 45 as grade IV (13.8\%). Monocurve contact lenses were successfully fitted in $66.1 \%$ of patients with grade I keratoconus, and $42.3 \%$ patients with grade II keratoconus $(\mathrm{P}<0.05$; Table 3). Of the 159 eyes classified as having mild (grade I) or moderate (grade II) keratoconus, monocurve RGPCL, bicurve lenses, and other lenses were fitted in $51.5 \%, 30 \%$, and $19 \%$ of cases, respectively $(P<0.05)$. Monocurve RGPCL and bicurve lenses were fitted in $26 \%$ and $55 \%$ of patients with advanced (grade III) or severe (grade IV), respectively $(P<0.05$; Table 4$)$.

In patients with oval cones, $45 \%$ were fitted with monocurve lenses, $35 \%$ with bicurve lenses, and 20\% with other lens types. In patients with round cones (nipple morphology), 55\% were fitted with bicurve lenses, 30\% with monocurve lenses, and $15 \%$ with other lens types $(\mathrm{P}<0.05$; Figure 1).

\section{DISCUSSION}

RGPCL remain an excellent option for visual rehabilitation of patients with keratoconus. In the present study, the corrected visual acuity of patients fitted with contact lenses was higher than those fitted with spectacles ( 0.2 vs. 0.5 logMAR). No statistically significant difference in the number of eyes classified as mild, moderate, advanced, or severe was observed in the present study.

Monocurve RGPCL were more frequently fitted in patients with grades I or II (51\%) than in those with grades III or IV (26\%; $\mathrm{P}<0.05)$, while bicurve lenses were fitted in the most advanced cases of keratoconus (30\% in grades I or II and 55\% in grades III or IV; $\mathrm{P}<0.05)$. In a retrospective study, Ghanem et al. analyzed 881 eyes with keratoconus and concluded that the majority could be fitted with rigid monocurve contact lenses. However, the results of the present study

\section{Table 1. Descriptive analysis of eyes studied and lens fitted}

\begin{tabular}{lc}
\hline Number of eyes $(n)$ & 325 \\
Patient age (years)* & $24.70 \pm 8.50$ \\
Base curve in soft contact lenses (D)* & $40.66 \pm 2.84 \mathrm{D}$ \\
Base curve in rigid contact lenses (D)* & $48.80 \pm 4.50 \mathrm{D}$ \\
K1 (D)* & $47.96 \pm 6.75 \mathrm{D}$ \\
K2 (D)* & $52.43 \pm 8.51 \mathrm{D}$ \\
Spectacle-corrected visual acuity $(\operatorname{logMAR})^{*}$ & $0.50 \pm 0.30$ \\
Contact lens-corrected visual acuity $(\operatorname{logMAR})^{*}$ & $0.20 \pm 0.10$ \\
\hline
\end{tabular}

Table 2. Design of fitted lenses

\begin{tabular}{lc}
\hline Contact lens design & $\%$ \\
\hline Monocurve & $38.8 \%$ \\
Bicurve & $42.4 \%$ \\
Multicurve & $13.8 \%$ \\
Other & $5.0 \%$ \\
\hline
\end{tabular}


Table 3. Association between the keratoconus evolution grade and type and design of contact lenses

\begin{tabular}{|c|c|c|c|c|c|c|c|c|c|c|c|c|}
\hline & \multicolumn{3}{|c|}{ Grade I } & \multicolumn{3}{|c|}{ Grade II } & \multicolumn{3}{|c|}{ Grade III } & \multicolumn{3}{|c|}{ Grade IV } \\
\hline$n$ & \multicolumn{3}{|c|}{62} & \multicolumn{3}{|c|}{97} & \multicolumn{3}{|c|}{121} & \multicolumn{3}{|c|}{45} \\
\hline$\%$ & \multicolumn{3}{|c|}{$19.07 \%$} & \multicolumn{3}{|c|}{$29.80 \%$} & \multicolumn{3}{|c|}{$37.20 \%$} & \multicolumn{3}{|c|}{$13.80 \%$} \\
\hline Design & $\mathbf{n}$ & $\%$ & $\begin{array}{c}\text { Diameter* } \\
(\mathrm{mm})\end{array}$ & $\mathbf{n}$ & $\%$ & $\begin{array}{c}\text { Diameter* } \\
(\mathrm{mm})\end{array}$ & $\mathbf{n}$ & $\%$ & $\begin{array}{c}\text { Diameter* } \\
(\mathrm{mm})\end{array}$ & $\mathbf{n}$ & $\%$ & $\begin{array}{c}\text { Diameter* } \\
(\mathbf{m m})\end{array}$ \\
\hline Monocurve & 41 & $66.1 \%$ & $9.20 \pm 0.20$ & 41 & $42.3 \%$ & $9.0 \pm 0.4$ & 36 & $29.8 \%$ & $8.9 \pm 0.4$ & 8 & $17.8 \%$ & $8.7 \pm 0.0$ \\
\hline Bicurve & 11 & $17.7 \%$ & $9.40 \pm 0.30$ & 36 & $37.1 \%$ & $9.3 \pm 0.3$ & 63 & $52.1 \%$ & $9.3 \pm 0.4$ & 28 & $62.2 \%$ & $9.2 \pm 0.4$ \\
\hline Multicurve & 1 & $1.6 \%$ & 8.7 & 13 & $13.4 \%$ & $8.7 \pm 0.1$ & 22 & $18.1 \%$ & $8.7 \pm 0.0$ & 2 & $20.0 \%$ & $8.9 \pm 0.3$ \\
\hline Multispherical & 4 & $6.5 \%$ & $10.00 \pm 0.20$ & 2 & $2.0 \%$ & $9.8 \pm 0.0$ & 0 & $0.0 \%$ & -- & 0 & $0.0 \%$ & -- \\
\hline Reverse curve & 0 & $0.0 \%$ & -- & 1 & $1.0 \%$ & 11.0 & 0 & $0.0 \%$ & -- & 0 & $0.0 \%$ & -- \\
\hline Hydrophilic & 4 & $6.5 \%$ & $14.10 \pm 0.30$ & 3 & $3.1 \%$ & $14.3 \pm 0.3$ & 0 & $0.0 \%$ & -- & 0 & $0.0 \%$ & -- \\
\hline Special hydrophilic for keratoconus & 1 & $1.6 \%$ & 14.2 & 1 & $1.0 \%$ & 14.2 & 0 & $0.0 \%$ & -- & 0 & $0.0 \%$ & --- \\
\hline
\end{tabular}

* $=$ average \pm standard deviation.

Table 4. Association between grade of keratoconus and design of fitted contact lenses

\begin{tabular}{lcc}
\hline & Grades I/II & Grades III/IV \\
\hline Monocurve & $51 \%$ & $26 \%$ \\
Bicurve & $30 \%$ & $55 \%$ \\
Other design* & $19 \%$ & $19 \%$ \\
\hline
\end{tabular}

*= hydrophilic contact lenses, keratoconus special hydrophilic contact lenses, multispherical lenses, and reverse curve design contact lenses.

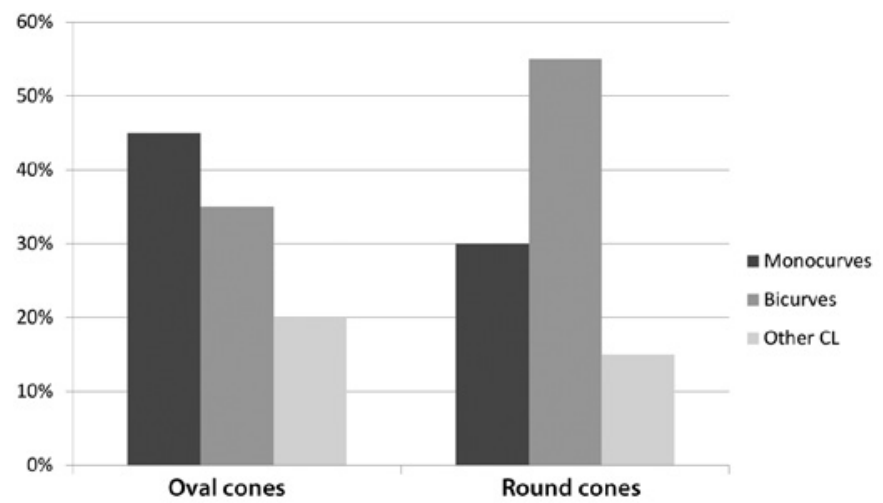

Figure 1. Frequency of fitted designs according to cone morphology.

indicate that other designs may be more appropriate in patients with more advanced and severe keratoconus. Toric contact lenses and the "piggyback"system were reported to be more suited to central cones, while monocurve and bicurve rigid contact lenses were more suited to inferior peripheral cones ${ }^{(8)}$. In addition, a separate study by the same group demonstrated that the design of contact lens used in the initial evaluation does not provide the best fit between the lens and cornea, due to variations in corneal topography over time. The Soper-McGuire lenses have been shown to be more effective than monocurve RGP$\mathrm{CL}$ in patients with advanced and central keratoconus ${ }^{(9)}$.

Cone morphology may influence the fitting of different lens designs. In the present study, monocurve lenses fitted oval cones better (45\%). However, a significant portion of eyes required bicurve lenses (35\%). Round cones mostly required bicurve lenses in order to achieve a better standard of adaptation (55\%).

\section{CONCLUSION}

Monocurve RGPCL were more frequently fitted in patients with mild to moderate keratoconus or with oval cone morphology, while bicurve lenses were more frequently fitted in patients with severe or advanced keratoconus, most likely as these lenses are considered the best option for patients with round cones due to increased corneal asphericity.

\section{REFERENCES}

1. Rabinowitz YS. Keratoconus. Surv Ophthalmol. 1998;42(4):297-319.

2. Krachmer JH, Feder RS, Belin MW. Keratoconus and related noninflammatory cornea thinning disorders. Surv Ophthalmol. 1984;28(4):293-322.

3. Romero-Jiménez M, Santodomingo-Rubido J, Wolffsohn JS. Keratoconus: a review. Cont Lens Anterior Eye. 2010;33(4):157-66.

4. Garcia-Lledo M, Feinbaum C, Alio JL. Contact lens fitting in keratoconus. Compr Ophthalmol Update. 2006;7(2):47-52.

5. Griffiths M, Zahner K, Collins M, Carney L. Masking of irregular corneal topography with contact lenses. CLAO J. 1998;24(2):76-81.

6. Lass JH, Lembach RG, Park SB, Hom DL, Fritz ME, Svilar GM, et al. Clinical management of keratoconus. A multicenter analysis. Ophthalmology. 1990;97(4):433-45.

7. Bilgin LK, Yilmaz S, Araz B, Yüksel SB, Sezen T. 30 years of contact lens prescribing for keratoconic patients in Turkey. Contact Lens Anterior Eye. 2009;32(1):16-21.

8. Ghanem VC, Ghanem CC, Ghanem RC, Larinho, C. Ceratocone: correlação entre grau evolutivo e padrão topográfico com o tipo de lente de contato adaptada. Arq Bras Oftalmol. 2003;66(2):129-35

9. Ghanem CC, Alves MR. Avaliação comparativa da adaptação de lentes de contato rígidas gás-permeáveis Monocurvas e Bicurvas (desenho Soper-McGuire) em pacientes portadores de ceratocone: um estudo prospectivo e randomizado. Arq Bras Oftalmol. 2008;71(3):328-36. 